\title{
DIFFERENTIATION OF BOVINE AND PORCINE GELATINES USING LC-MS/MS AND CHEMOMETRICS
}

\section{NINA SALAMAH ${ }^{1,2}$, YUNY ERWANT0 ${ }^{3,4}$, SUDIBYO MARTONO'1, IRFAN MAULANA ${ }^{5}$, ABDUL ROHMAN 1,4*}

1Department of Pharmaceutical Chemistry, Faculty of Pharmacy, Universitas Gadjah Mada, Yogyakarta, 55281, Indonesia, ${ }^{2}$ Faculty of Pharmacy, Ahmad Dahlan University, Yogyakarta, Indonesia, ${ }^{3}$ Faculty of Animal Sciences, Universitas Gadjah Mada, Yogyakarta 55281, Indonesia, ${ }^{4}$ Institute of Halal Industry and Systems, Universitas Gadjah Mada, Yogyakarta, 55281, Indonesia, 5 MS Senior Application Chemist, PT. Kromtekindo Utama “Waters Indonesia" Jakarta 12330, Indonesia

Email: abdul_kimfar@ugm.ac.id

Received: 10 Oct 2018, Revised and Accepted: 26 Apr 2019

\section{ABSTRACT}

Objective: To differentiate porcine gelatin and bovine gelatins using specific peptide markers as determined by liquid chromatography-mass spectrometry tandem with mass spectrometry (LC-MS/MS) and classify both gelatins using retention time and $\mathrm{m} / \mathrm{z}$ as variables in principal component analysis (PCA).

Methods: Porcine and bovine gelatins were digested using trypsin enzyme and then subjected to LC-MS/MS analysis. The specific peptides were identified. The classification between porcine and bovine gelatins was carried out using chemometrics of PCA using retention times and mass to charge ratio $(\mathrm{m} / \mathrm{z})$ as variables.

Results: PCA using singvariables retention times $\left(t_{R}\right)$ and $m / z$ could successfully classify porcine gelatin and bovine gelatin based on score plots of first principle component (PC1) and second principle component (PC2). The loading plot analysis showed that variable of $\mathrm{t}_{\mathrm{R} 32}$ and $\mathrm{m} / \mathrm{z}_{32}$ contributed for the separation of both gelatins.

Conclusion: The chromatograms of LC-MS/MS combined with PCA offered reliable method for differentiation between porcine and bovine gelatins. The developed method could be extended for halal authentication of food and pharmaceutical products via detection of porcine gelatin, non-halal gelatin.

Keywords: LC-MS/MS, Porcine gelatin, Bovine gelatin, Principal component analysis, Classification

(C) 2019 The Authors. Published by Innovare Academic Sciences Pvt Ltd. This is an open-access article under the CC BY license (http://creativecommons.org/licenses/by/4.0/) DOI: http://dx.doi.org/10.22159/ijap.2019v11i4.30248

\section{INTRODUCTION}

Gelatin, a mixture of polypeptides obtained from hydrolysis of collagen with high molecular weight (MW), is commonly used in the food industry because of its gelling and thickening properties and pharmaceutical industry to prepare hard and soft capsule shells as well as in cosmetics products [1-3]. High MW of gelatines affected gel strength and viscosity of products [4]. Numerous sources for extraction of collagen have been reported, most ones are porcine, bovine, and fish. The Muslim societies following certain scholars of thought did not allow the consumption of any products containing porcine gelatine (PG) and considered PG as non-halal materials [5], while bovine gelatine (BG) carrying prion proteins is associated with certain diseases like bovine spongiform encephalopathy [6]. It is also reported that specific response of immune can occur in the case of gelatines coming from certain sources, therefore, these gelatines are inappropriately used [7]. As a consequence, there is a need to develop reliable methods for identifying gelatine sources in any products.

Several methods have been developed, validated and used for differentiation, classification, and identification of gelatine origins. Some reviews also existed reporting analytical methods for authentication analysis of gelatines either in raw materials or in food and pharmaceutical products [8-10]. Such methods are immunochemical method used for identification of collagen origins, but this method could be affected by the hydroxylation amount of amino acid of proline, which capable of playing an important role in determining the collagen antigenicity [11], Fourier transform infrared spectroscopy [12], however, this method was only used for certain composition, real-time polymerase chain reaction (PCR) method for identification of certain species DNA present in gelatines, but sometimes the integrity of DNA is destroyed during processing of products containing gelatine [13, 14], and high-performance liquid chromatography coupled with uv-vis detector, but this method could not find specific markers for gelatine differentiation $[15,16]$. HPLC method analyzed amino acids as a results of hydrolysis of collagen, however, amino acids do not inhibit specific markers in gelatines composition. Alternatively, analysis of specific peptide markers, combined with chemometrics, allows the differentiation between porcine and bovine gelatines $[17,18]$. In this study, liquid chromatography-mass spectrometry tandem with mass spectrometry (LC-MS/MS) in combination with chemometrics was developed for differentiation of porcine and bovine gelatines.

\section{MATERIALS AND METHODS}

\section{Materials}

Porcine gelatin and bovine gelatin were obtained from Sigma (Alldrich, USA). Trypsin with sequencing grade was purchased from Promega (Madison, WI, USA). The syringe filter $(0.22 \mu \mathrm{m})$ was bought from Millipore (Billerica, MA, USA). The solvents used for LCMS/MS analysis were of LC-MS grade. The reagents and solvents used were of pro-analytical grade.

\section{Digestion of gelatins}

Digestion of gelatines was performed using trypsin according to Cheng et al. [20]. A-100 mg standard gelatines (porcine and bovine gelatines) was dissolved in $50 \mathrm{ml}$ ammonium bicarbonate $\left(\mathrm{NH}_{4} \mathrm{HCO}_{3}\right.$ $1 \%, \mathrm{pH} 8.0$ ). The solution was filtered using syringe filter $0.22 \mu \mathrm{m}$. After that, $100 \mu \mathrm{L}$ gelatine solutions was taken and added with $10 \mu \mathrm{L}$ trypsin $\left(1 \mathrm{mg} / \mathrm{ml}\right.$ in $\mathrm{NH}_{4} \mathrm{HCO}_{3} 1 \%, \mathrm{pH}$ 8.0). The solution was incubated at $37^{\circ} \mathrm{C}$ for $12 \mathrm{~h}$ and subjected to LC-MS/MS analysis.

\section{Analysis of peptides using LC-MS/MS}

Separation of peptides was performed using ACQUITY UPLC H-Class equipped with a detector of mass spectrometer tandem with mass spectrometer. The analytical column used was ACQUITY UPLC peptide CSH ( $100 \times$ x 2,1 mm i. d; 1,7 $\mu \mathrm{m}$ ) with temperature of column of $65{ }^{\circ} \mathrm{C}$. The mobile phase was $\mathrm{H}_{2} \mathrm{O}$ containing trifluoroacetic acid $0.1 \%(\mathrm{~A})$ and acetonitrile containing trifluoroacetic acid $0.1 \%$ (B) and delivered in a gradient manner as follows: 
Table 1

\begin{tabular}{llll}
\hline Time (min) & Flow (ml/min) & \%A & \%B \\
\hline Initial & 0.20 & 97 & 3 \\
3.00 & 0.20 & 97 & 3 \\
120.00 & 0.20 & 65 & 35 \\
127.00 & 0.20 & 20 & 80 \\
130.00 & 0.20 & 20 & 80 \\
131.00 & 0.20 & 97 & 3 \\
140.00 & 0.20 & 97 & 3 \\
\hline
\end{tabular}

For MS/MS condition: sample rate of 2 points/sec, mass range of 350-1250 Da, cone voltage of $10 \mathrm{~V}$, capillary voltage of $1.5 \mathrm{kV}$, and probe temperature of $500^{\circ} \mathrm{C}$.

\section{Chemometrics analysis}

The chemometrics of principal component analysis (PCA) was used for classification of porcine and bovine gelatins. PCA is unsupervised pattern recognition technique commonly used for sample classification, based on certain variables. PCA was done using Minitab software version 17 (Minitab Inc., USA).

\section{RESULTS AND DISCUSSION}

The previous study reported that profiling of peptides in gelatin samples was accomplished within $120 \mathrm{~min}$. In this study, the differentiation of porcine and porcine gelatins was run within longer analytical time to allow complete separation of peptides. The first step for differentiation between porcine gelatin and bovine gelatin using liquid chromatography-mass spectrometry tandem mass spectrometry (LC-
MS/MS) was digestion of gelatines with proteolytic enzyme of trypsin. Trypsin cleaves the peptide bond between the carboxyl group of arginine (R) or the carboxyl group of lysine (K) and the amino group of the adjacent amino acids [19], as shown in fig. 1.

With LC, the obtained peptides would be separated based on an interaction between peptides and stationary phase, as indicated with certain retention times. Fig. 2 revealed LC chromatograms of peptides obtained from digestion of porcine gelatin and bovine gelatin. In addition, fig. 3 revealed LC chromatogram of peptides in porcine gelatin mixed with bovine gelatin previously digested using trypsin. The results of this study exhibited that it is possible to differentiate the peak markers playing an important role in such differentiation, corresponding to specific peptides composed of porcine and bovine gelatins.

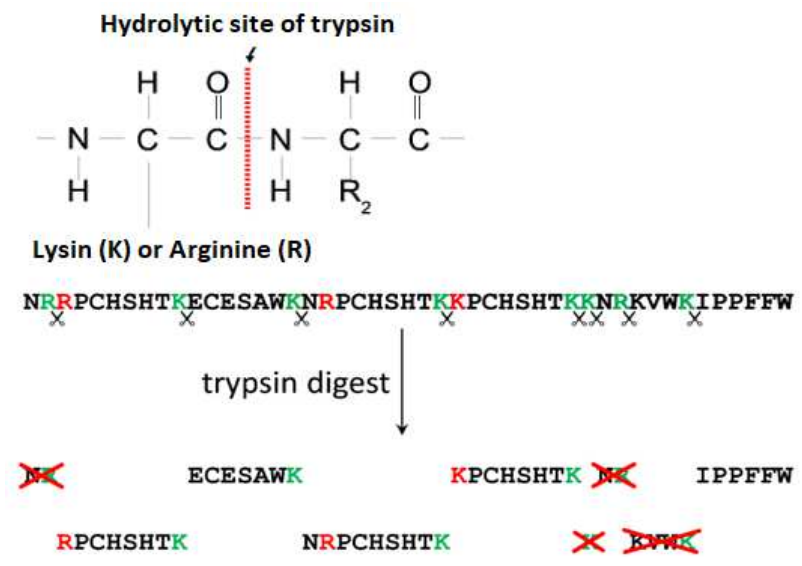

Fig. 1: Hydrolysis of gelatin using trypsin which cleavage the peptide bond between the carboxyl group of arginine (R) or the carboxyl group of lysine $(\mathrm{K})$ and the amino group of the adjacent amino acid [19]

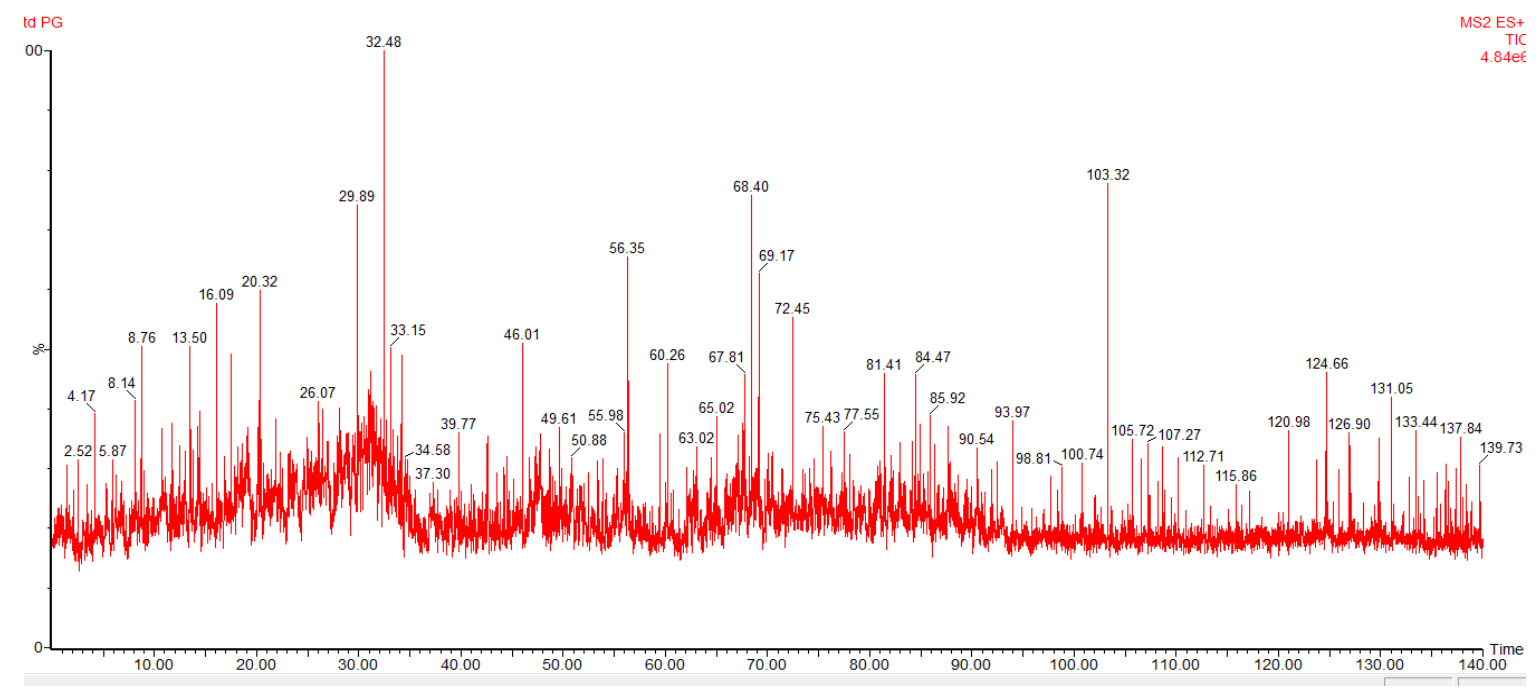




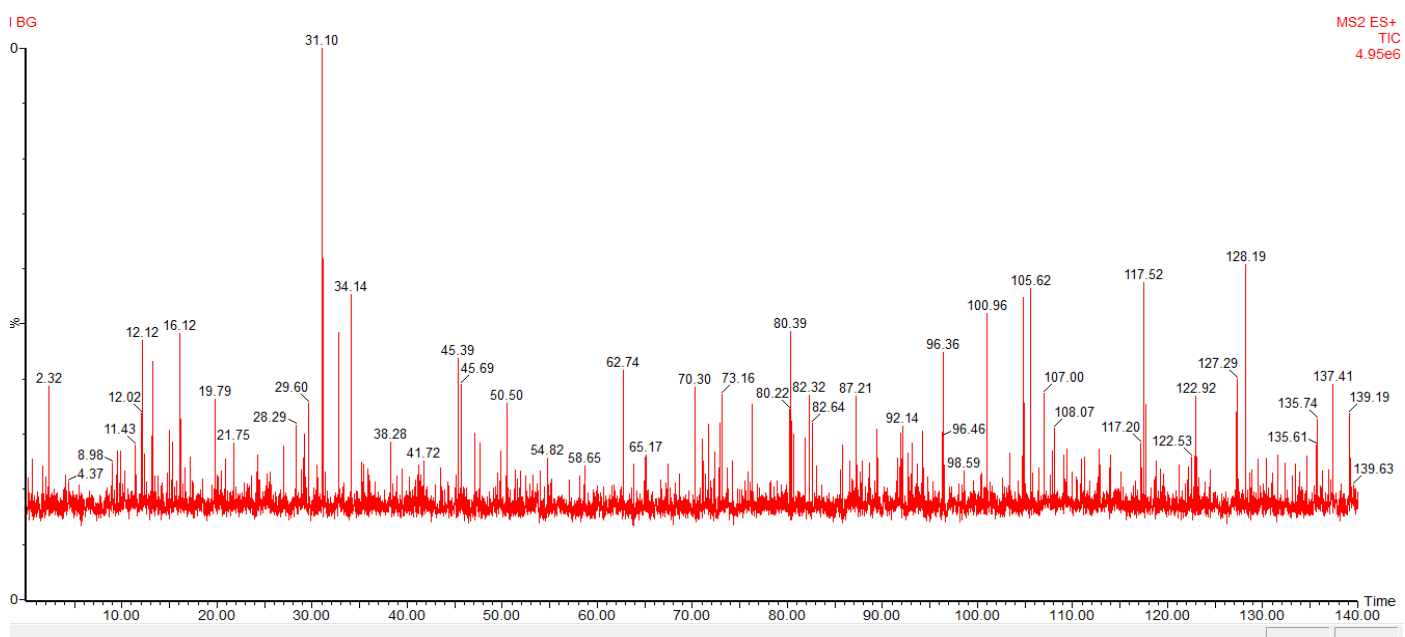

Fig. 2: The LC chromatograms of peptides obtained from digestion with trypsin enzyme of porcine gelatin (above) and bovine gelatin (below)

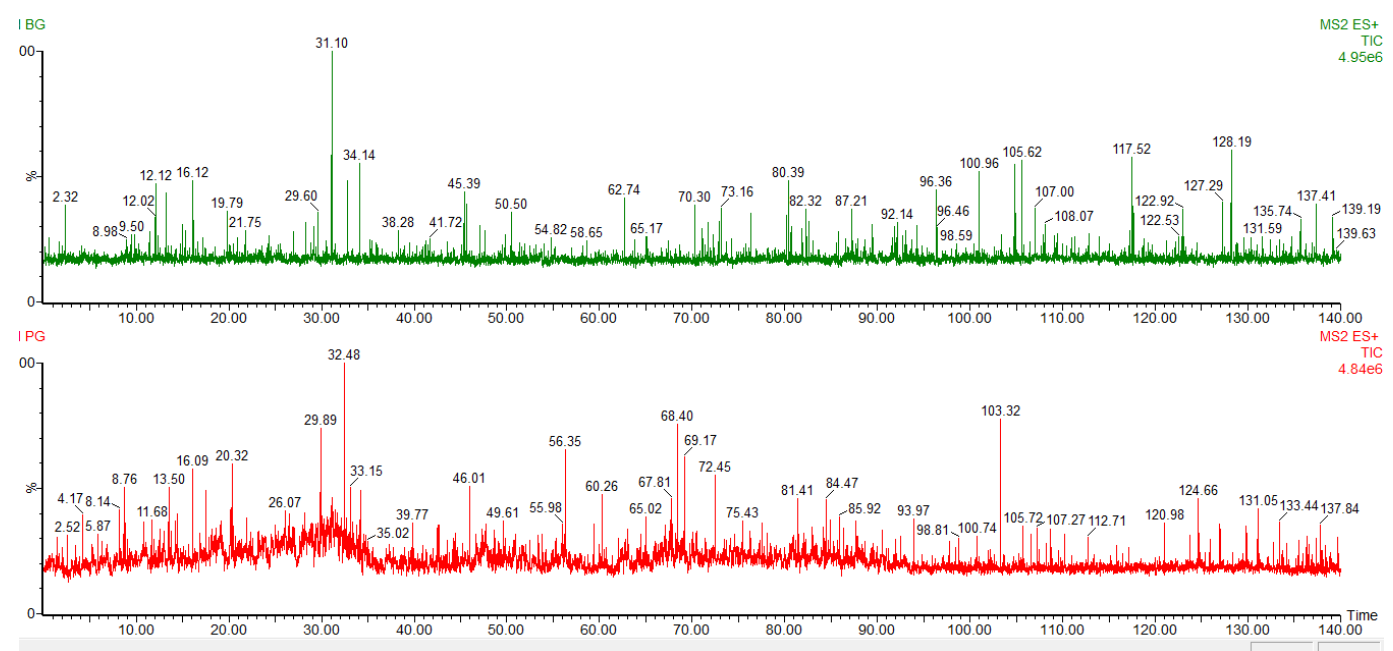

Fig. 3: The LC chromatograms of peptides obtained from digestion with trypsin of the mixture of bovine gelatin (above) and porcine gelatin (below)

Mass spectra of each peaks with specific retention time indicated peptides with certain fragmentation pattern. Fig. 4 was an example of fragmentation pattern of peptides obtained from porcine gelatin digested with trypsin at retention time (tR) of 3.1 with main peak with maximum abundance at $\mathrm{m} / \mathrm{z}=972$, along with other ion fragments.

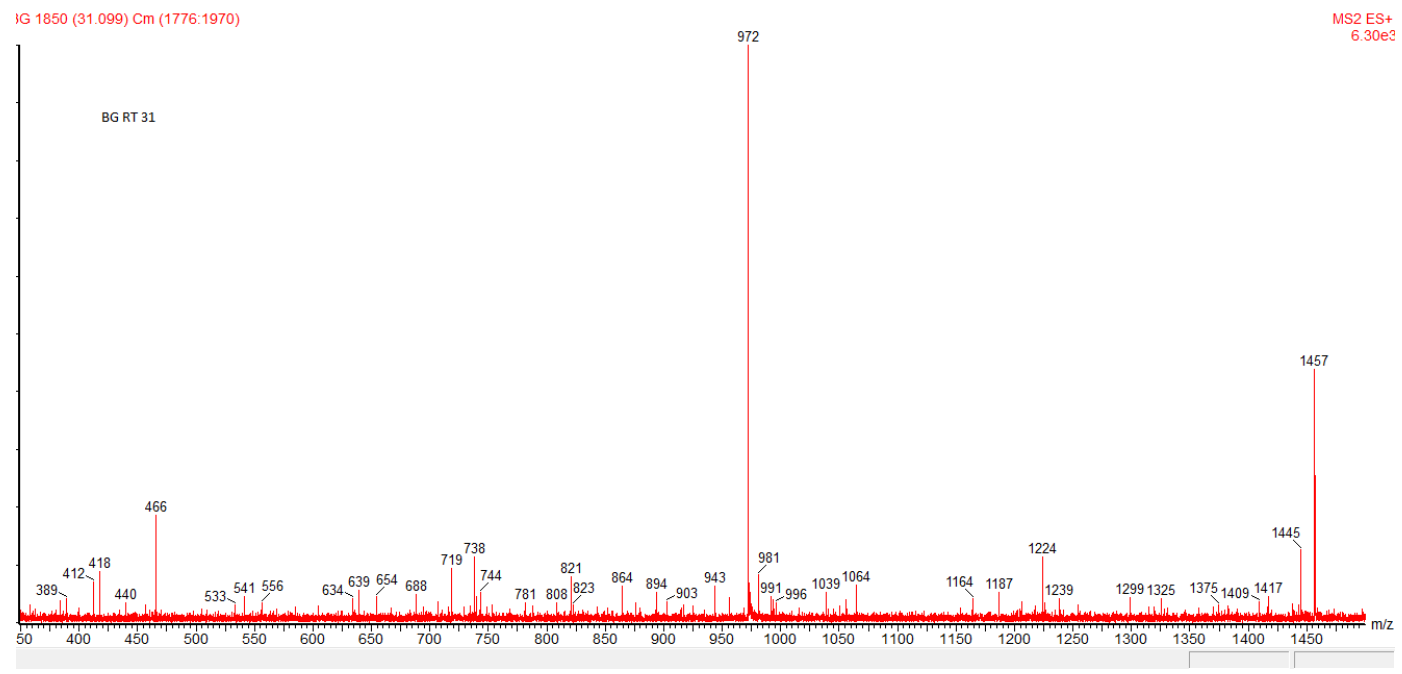

Fig. 2: The MS/MS profiles of specific peptides of porcine gelatin digested with trypsin at retention time $\left(t_{R}=3,1\right)$ 
It appears that the peak markers corresponding to peptides present in evaluated gelatines were indistinguishable because of some peaks appeared in both gelatines. Therefore, it is difficult to distinguish each gelatine types by visual observation of corresponding chromatograms. Therefore, advance classification techniques should be used. In order to classify between porcine gelatine and bovine gelatine, the chemometrics of principal component analysis (PCA) was used. PCA is one the unsupervised pattern recognition techniques commonly used for grouping of sample objects. PCA could project the initial variable data in reduced dimensions defined by the principal components (PC). The value corresponding to PC is known as a score plot. PCA technique is useful when there are correlations present among variables [21]. In this study, PCA was accomplished using retention time and $\mathrm{m} / \mathrm{z}$ of LC-MS/MS chromatograms as variables. Fig. 5 exhibited PCA score plots of gelatines (porcine and bovine) representing the projection of sample objects defined by the first principle component (PC1) and second principle component (PC2), using $t_{R}(A)$ and $\mathrm{m} / \mathrm{z}(\mathrm{B})$ as variables. PC1 accounts for the most variation in initial variables ( $\mathrm{t}_{\mathrm{R}}$ and $\mathrm{m} / \mathrm{z}$ ), while PC2 accounts for the next largest variation. From fig. 5, it is clear that both gelatines could be separated successfully and easily differentiated using PC1 and PC2 score plots.
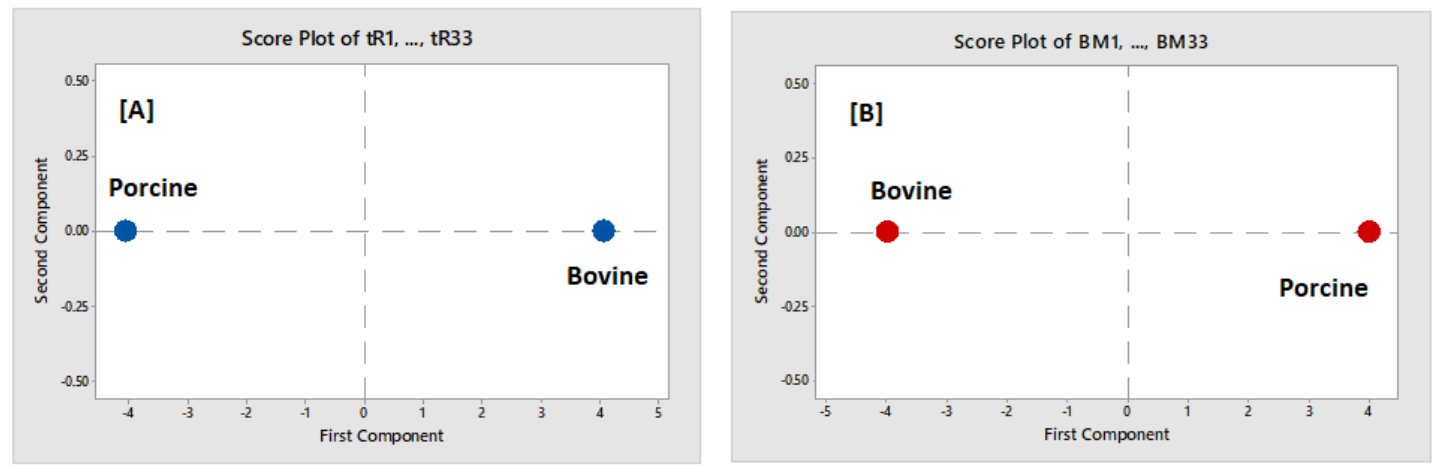

Fig. 5: The score plot for the first principal components (PC1) and second principle component (PC2) for bovine and porcine gelatins

In order to evaluate the variables contributing to the separation of porcine and bovine gelatins, loading plot analysis was carried out. The PCA loading plot explains the projection of variables used during PCA in the same plane as the score plot. The absolute value of loading in the variables ( $t_{R}$ and $\mathrm{m} / \mathrm{z}$ ) explains the importance of the contribution of each region. Therefore, the further away $t_{R}$ and $m / z$ from the origin of variable point, the larger the contribution of that variable to the PCA model [22]. The results of loading plot indicated that tR32 and m/z32 make a larger contribution to the PCA model.

\section{CONCLUSION}

LC-MS/MS in combination with chemometrics of principal component analysis (PCA) using variables of retention time $\left(t_{R}\right)$ of LC chromatogram and mass to charge ratio $(\mathrm{m} / \mathrm{z})$ could classify porcine gelatin from bovine gelatin fruitfully. The variable of $t_{R 32}$ and $\mathrm{m} / \mathrm{z}_{32}$ contributed significantly for the classification of both gelatin. The developed method could be proposed as a standard method for identification of porcine gelatin for halal authentication analysis.

\section{ACKNOWLEDGMENT}

The authors thank to Ministry of Research and Higher Education (kemenristekdikti), Republic of Indonesia for financial support via research scheme of Desentralisasi Penelitian Terapan Unggulan Perguruan Tinggi.

\section{AUTHORS CONTRIBUTIONS}

NS, SM, SR and AR designed research, prepared manuscript and made critical thinking on the manuscript. NS and AR performed research activities and analysed data.

\section{CONFLICTS OF INTERESTS}

Declared none

\section{REFERENCES}

1. Li GY, Fukunaga S, Takenouchi K. Comparative study of the physiological properties of collagen, gelatin and collagen hydrolysate as cosmetic materials. Int J Cosmet Sci 2005;27:101-6.

2. Poppe J, In: A Immeson. Ed. Gelatin in Thickening and Gelling Agents for Food, Blackie, London; 1992. p. 98-123.

3. Shoshani D, Markovitz E, Cohen Y. Skin test hypersensitivity study of a crosslinked, porcine collagen implant for aesthetic surgery. J Periodontol 2007;78:112-21.
4. Gómez Guillen MC, Gimenez B, Lopez Caballero ME, Montero MP. Functional and bioactive properties of collagen and gelatin from alternative sources: a review. Food Hydrocolloids 2011;25:1813-27.

5. Mursyidi A. The role of chemical analysis in the halal authentication of food and pharmaceutical products. J Food Pharm Sci 2013;1:1-4.

6. Widyaninggar A, Triyana K, Rohman A. Differentiation between porcine and bovine gelatin in capsule shells based on amino acid profiles and principal component analysis. Indonesian J Pharm 2012;23:104-9.

7. Sakaguchi M, Nakayama T, Inouye S. Food allergy to gelatin in children with systemic immediate-type reactions, including anaphylaxis, to vaccines. J Allergy Clin Immunol 1996;98:1058-61.

8. Nhari RMHR, Ismail A, Che Man YB. Analytical methods for gelatin differentiation from bovine and porcine origins and food products. J Food Sci 2012;77:R42-6.

9. Rohman A, Che Man YB. Analysis of pig derivatives for halal authentication studies. Food Rev Int 2012;28:97-112.

10. Ali ME, Sultana S, Hamid SBA, Hossain M, Yehya WA, Kader A, et al. Gelatin controversies in food, pharmaceuticals, and personal care products: authentication methods, current status, and future challenges. Crit Rev Food Sci Nutr 2016;58:1-17.

11. Venien A, Levieux D. Differentiation of bovine from porcine gelatines using polyclonal anti-peptide antibodies in indirect and competitive indirect ELISA. J Pharm Biomed Anal 2005;39:418-24.

12. Hashim DM, Che Man YB, Norakasha R, Shuhaimi M, Salmah Y, Syahariza ZA. Potential use of fourier transform infrared spectroscopy for differentiation of bovine and porcine gelatins. Food Chem 2010;118:856-60.

13. Kauschke SG, Knorr A, Heke M. Two assays for measuring fibrosis: reverse transcriptase-polymerase chain reaction of collagen alpha (III) mRNA is an early predictor of subsequent collagen deposition while a novel serum Nterminal procollagen (III) propeptide assay reflects manifest fibrosis in carbon tetrachloride-treated rats. Anal Biochem 1999;275:131-40.

14. Sudjadi, Wardani HS, Sepminarti T, Rohman A. Analysis of porcine gelatin DNA in a commercial capsule shell using realtime polymerase chain reaction for halal authentication. Int J Food Prop 2016;19:2127-34.

15. Nemati M, Oveisi MR, Abdollahi H, Sabzevari O. Differentiation of bovine and porcine gelatins using principal component analysis. J Pharm Biomed Anal 2004;34:485-92. 
16. Azilawati MI, Hashim DM, Jamilah B, Amin I. RP-HPLC method using 6-aminoquinolyl-N-hydroxysuccinimidyl carbamate incorporated with normalization technique in principal component analysis to differentiate the bovine, porcine and fish gelatins. Food Chem 2015;172:368-76.

17. Zhang GF, Liu T, Wang Q, Chen L, Lei JD, Luo J, et al. Mass spectrometric detection of marker peptides in tryptic digests of gelatin: a new method to differentiate between bovine and porcine gelatin. Food Hydrocoll 2009; 23:2001-7.

18. Zhang GF, Sun AM, Li WJ, Liu T, Su ZG. Mass spectrometric analysis of enzymatic digestion of denatured collagen for identification of collagen type. J Chromatogr A 2006; 1114:274-7.
19. Olsen JV, Ong SE, Mann M. Trypsin cleaves exclusively cterminal to arginine and lysine residues. Mol Cell Proteomics 2014;3:608-14.

20. Cheng XL, Wei F, Xiao XY, Zhao YY, Shi Y, Liu W, et al. Identification of five gelatins by ultra performance liquid chromatography/time-of-flight mass spectrometry (UPLC/QTOF-MS) using principal component analysis. J Pharm Biomed Anal 2012;62:191-5.

21. Che Man YB, Rohman A, Mansor TST. Differentiation of lard from other edible fats and oils by means of fourier transform infrared spectroscopy and chemometrics. J Am Oil Chem Soc 2011;88:187-92.

22. Marina AM, Che Man YB, Ismail A. Use of the SAW sensor electronic nose for detecting the adulteration of virgin coconut oil with RBD palm kernel olein. J Am Oil Chem Soc 2010;87:263-70. 